\title{
Design, Frugal Innovations and Low-Resource Settings: An Analysis of Five Contextual Aspects
}

\author{
Santosh Jagtap
}

\begin{abstract}
Designing frugal innovations is crucial to alleviate problems faced by people living in low resource settings. Many design studies have been undertaken in such low resource settings. These studies are discussed using a variety of names such as 'frugal innovations', 'appropriate technology', 'design for the Base of the Pyramid (BOP)', 'product service systems for BOP', 'community development engineering', 'design for development', etc. There is an important need to know in what context these studies were undertaken. In order to gain an in-depth understanding of the contextual aspects of these studies, we review a wide range of literature, focussing on design studies in this field. The review findings show a multifaceted picture, revealing a large variety in examination and presentation of contextual aspects such as income, design sectors, countries, rural-urban, and gender. Based on the review findings, we offer recommendation for practice, education and research of designing frugal innovations in low resource settings.
\end{abstract}

Keywords Design process, Product Service Systems, Base of the Pyramid, Frugal Innovations, Low Resource Settings, Context

\section{Introduction}

People living in low resource settings in developing countries face numerous problems. Their income is irregular and unpredictable (World Bank, 2010). They generally live in shanty towns, urban slums, or rural villages, and have little or no formal education. They typically lack access to basic facilities including, among others, clean water, infrastructure, sanitation, public health, and energy. They are generally not good at saving and investing, and prefer immediate consumption. This short-term approach can be due to their weak access to various resources and assets (e.g. Jagtap et al., 2013).

Design, with its core idea of changing an existing or undesired state into a desired state, has a prominent role in satisfying unmet or under-served needs of people living in low resource settings at the base of the world income pyramid, typically known as the Base of the Pyramid (BOP). Alleviating poverty or satisfying needs of BOP people demands the design of frugal innovations, which can manifest in several forms such as products, services or product service systems (e.g. Jagtap and Larsson, 2013).

\author{
S. Jagtap \\ Blekinge Institute of Technology, Sweden \\ e-mail: santosh.jagtap@iitb.ac.in; snjagtap22@gmail.com
}

International Conference on Research into Design, ICoRD 2021, IIT Bombay, Mumbai, India 
Some examples of such frugal innovations are medical devices, educational devices, income-generating products or services, vaccination plans, systems supporting agriculture and water distribution, or any other products and services that support social and human development of BOP individuals and communities. Design of these frugal innovations is undertaken, for example, by NGOs, governments, for-profit companies, and BOP people as well (e.g. Prahalad, 2004; Jagtap and Larsson, 2013).

Whilst design research has been predominantly undertaken in Western countries or relatively affluent regions (Jagtap, 2019c), many design studies have been undertaken in the context of BOP societies in developing countries. These design studies in the BOP context are discussed using names such as 'frugal innovations', 'appropriate technology', 'design for the Base of the Pyramid', 'product service systems for the BOP', 'community development engineering', 'design for development', etc. (e.g. Donaldson, 2009; Jagtap et al., 2013). Furthermore, several universities have begun to offer projects or courses in this field, while undertaking design investigation to understand and support design for supporting social and human development of the BOP (e.g. Jagtap et al., 2014a).

Whilst several design studies have been undertaken in this field, there is absence of their analysis, making it difficult to gain an understanding of context in which they were carried out. Since design is a context-specific activity, it is crucial to gain an overview of contextual aspects (e.g. countries, rural-urban, design sectors, etc.) of these studies. Therefore, we aim at analysing contextual aspects of these studies. This is addressed by reviewing the relevant literature, focusing on contextual aspects of the studies. Analysing and scrutinising contextual aspects of the design studies is crucial in undertaking further design research in this field and in developing and testing methods and tools to support practice and education of designing frugal innovations. We identify crucial areas that are still not explored, offering recommendations for design research this field. Our purpose is to explain some of its current issues and to suggest areas for scholarly exploration of this field.

Following this introduction, the rest of the paper is organised as follows. Section 2 presents an overview of design research in BOP societies. Section 3 presents the research methodology employed. Section 4 discusses five contextual aspects as revealed in this review. Finally, Section 5 discusses the review findings, offering suggestions for future research in this field.

\section{Design, Frugal Innovations and Low Resource Settings}

'Design for the Real World' and 'Appropriate Technology' concepts, articulated in the 1970s, by Victor Papanek and E. F. Schumacher, respectively, can be considered as early attempts of employing design to support development of BOP societies (Papanek and Fuller, 1972; Schumacher, 1973). Papanek's movement suggested designers to undertake projects for satisfying needs of people in developing countries. The appropriate technology movement, motivated by the failures in transferring products and technologies from industrialised to developing countries, suggested designing suitable technologies, contextualised for societies in developing countries. The 
appropriate technology movement could not deliver expected impact in addressing problems of marginalised societies in developing countries.

In the case of the 'Design for the Real World' and 'Appropriate Technology' movements, the role of NGOs in undertaking design projects can be recognised. On the other hand, the roles of multinational corporations (MNCs) is explicit in the BOP concept articulated by Prahalad and his colleagues in 1998-1999 (Prahalad and Hart, 1999). In parallel to the BOP concept, a complimentary concept, known as 'subsistence marketplaces' approach, articulated by Viswanathan and his colleagues evolved (e.g. Viswanathan and Rosa, 2007). In this approach, they have developed a bottomup approach for designing solutions to address needs of BOP individuals and societies.

In recent years, research on the design of affordable products and services using several terms such as 'frugal innovation', 'jugaad innovation' and 'grass root innovation' is developing (e.g. Gupta, 2016; Radjou et al., 2012). These innovations generally consider creating highly affordable and low-cost innovations in a low resource setting. Furthermore, similar concepts using names such as community development engineering, humanitarian engineering, engineering for development, and design for extreme affordability are growing (e.g. Nielsen, 2008). Engineering and design departments in many universities support and carry out design projects, while offering courses in this field (Jagtap et al., 2014). This has resulted into many design studies undertaken in the BOP context.

\section{$3 \quad$ Research methodology}

Design investigations in the BOP context have been carried out in several contexts in many developing countries. Since design is a social process (e.g. Minneman and Leifer, 1993; Bucciarelli, 1994), with close connection between design practice and the context of the practice, it is important to examine contextual aspects of the studies. This analysis of contextual aspects is useful in understanding similarities and differences between contexts researched in various studies. We searched databases such as Scopus, Web of Science and Google Scholar to search for design studies in this field. This paper discusses a broad range of studies, with close analysis of 30 papers, focusing on their contextual aspects (e.g. income, design sectors, countries, rural-urban, and gender). Of the 30 papers, 25 are journal and 5 are conference papers. The journal papers are published in outlets such as 'Co-Design', 'Design Studies', 'Engineering Studies', 'Research in Engineering Design', 'Technology in Society', 'International Journal of Design', 'Design Management Review', 'Journal of Product Innovation Management', 'Design Issues', 'Journal of Mechanical Design', etc. The 30 papers present studies that have been undertaken from design perspective, e.g. studies aimed at understanding and supporting how products, systems and services are designed in the BOP context. This selection of articles allowed a focused approach, permitting their close analysis. Due to the constraint on the number of pages allowed in this paper, we have not included the list of 30 papers. This list is available in our previous study (Jagtap, 2019a). 


\section{Contextual Aspects in Designing Frugal Innovations}

The reviewed studies consider contextual aspects such as rural or urban region, income of BOP people, design sectors, specific developing countries, and gender aspects. These contextual aspects ought to be considered in undertaking design research in BOP societies, and in developing and evaluating methods and tools to create intended impact on design practice in this field (e.g. Jagtap et al., 2013; Aranda-Jan et al., 2016). These contextual aspects are discussed in the following subsections.

\subsection{Income}

Income is a quantifiable measure of poverty. Income enables people to buy products and services and permits them to fulfil basic needs, reducing their vulnerability and powerlessness. Therefore, income-based measurement of poverty has received attention (Karnani, 2011). Some of the reviewed studies have defined or reported income. For instance, income level of $\$ 4$ a day is reported in Jagtap et al. (2013). Murcott (2007) and Thomas (2006) define the level of $\$ 1$ a day in their paper. Whilst there is diversity and inconsistency in reporting and defining income, these studies provide some information on the examined contexts. Studies not mentioning or defining income threshold leave much room for interpreting the context. This also makes it difficult to compare contexts examined in such studies.

In addition to income, qualitative aspects of poverty also provide important insights into the examined contexts. Many studies qualitatively report other dimensions of poverty. For example, poverty has been described as social, cultural and political exclusion, in terms of various constraints and deprivations, in terms of problems of gender inequality, or in terms of vulnerability due to effects of climate-changes (e.g. Jagtap and Larsson, 2013; Narayan et al., 2000). Such qualitative aspects expand the concept of poverty measurement from income-based to multidimensional construct. Overall, it is crucial to describe qualitative characteristics of the context and define or report income.

\subsection{Rural and Urban}

Using the Multidimensional Poverty Index (MPI), Alkire et al. (2014) compared rural and urban poverty, revealing differences in various characteristics of poverty in these areas. The three dimensions - education, health and standard of living — are taken into account in the estimation of the MPI. These three dimensions are assigned equal weights. Whilst greater prevalence of poverty is seen in rural than urban areas, poor people from rural regions are migrating to urban areas. Deprivations in electricity, water, and flooring contribute more to MPI in the case of rural poverty. On the other hand, deprivations in school attendance, child-health and nutrition contribute more in the case of urban poverty (Alkire et al., 2014). Furthermore, social networks of poor people in urban areas are relatively weak, and they face problems of crime and social unrest. 
Design studies are undertaken in both rural and urban areas of developing countries. For example, Whitney and Kelkar (2004) have undertaken an ethnographic design study in urban slums in India and Guimarges et al. (1996) studied how small firms in urban areas in Brazil design products. In addition to studies in urban areas, many studies have been undertaken in rural areas. For example, Nieusma and Riley (2010) examined how engineering designers consider cultural and technological aspects in designing products for marginalised communities. As a part of their study, they undertook a case study in a rural village in Sri Lanka. Their findings suggest that there is a tendency to consider mainly technological factors, with less emphasis on the issues related cultural and social aspects. Design studies have also dealt with the design of pumps and irrigation systems to support farmers in their agricultural activities (e.g. Jagtap and Kandachar, 2010). It is important to direct design efforts for alleviating poverty in both rural and urban areas, taking into account specific requirements and problems in these areas (e.g. Jagtap, 2019a). For example, since rural village in developing countries can be geographically dispersed, issues of marketing and distribution need to be handled carefully in designing frugal innovations for rural areas. Whilst studies have been undertaken in both rural and urban areas of developing countries, the literature has just presented general guidelines to design frugal innovations for people in these areas.

\subsection{Design sectors}

Although design studies have been carried out in several sectors such as healthcare, water, energy, etc., several cases are drawn from some specific sectors, in particular, from sectors such as artisanal-goods, information and communication technologies (ICTs), healthcare, and water. For instance, in healthcare sector, some studies have aimed at supporting designers to generate concepts for healthcare devices or to develop holistic understanding of target community (e.g. Aranda-Jan et al., 2016). In a similar fashion, studies in artisanal-goods and ICTs sectors, for example, have developed methodologies to support design activities of craftspeople or to support the development of ICTs for marginalised societies (e.g. Girón et al., 2004; Cai et al., 2007).

Studies such the above, have been carried out in one of the sectors. On the other hand, some studies have explored several design sectors. For example, by analysing data from the Growing Inclusive Markets (GIM) initiative of the United Nations Development Programme (UNDP), Jagtap et al. (2013) examined strategies used by businesses in designing and developing frugal innovations for the BOP. Likewise, by analysing studies from several sectors, guidelines have been developed to aid the design of integrated frugal innovations for BOP societies (Jagtap, 2019b).

\subsection{Countries}

There is variation in poverty rates across developing couriers. In some developing countries, poverty rates have increased (Olinto et al., 2013). The Development Assistance Committee (DAC) of the Organisation for Economic Co-operation and Development (OECD) has categorised developing countries into four types - 'least devel- 
oped', 'low income', 'lower middle income', and 'upper middle income'. The classification of developing countries into 'low income', 'lower middle income', and 'upper middle income' categories is based on the Gross National Income per capita. The 'least developed' countries are "the poorest and weakest segment of the international community", representing approximately 12 percent of the global population and supporting not more than 2 percent to the world GDP (UN, 2017).

Several studies are carried out in, or use or refer to secondary data, from India - a 'lower middle income' country (for example, see Subrahmanian et al., 2017). From the 'least developed' category, studies are carried out mainly in Nepal, Bangladesh, and Cambodia (e.g. Murcott, 2007; Kang, 2016). Similarly, from the 'upper middle income' category, studies focus primarily on South Africa and Brazil. From the 'low income' category, studies are undertaken in Zimbabwe and Kenya (e.g. Thomas, 2006; Donaldson, 2006). Findings of a few studies are applicable to developing countries in general (e.g. Aranda Jan et al., 2016; Wicklein, 1998). However, there is a need of category-related or country-related design guidelines.

\subsection{Gender}

As compared to men living in poverty, women living in poverty face numerous problems, weakening their access to, for example, healthcare and education (e.g. Cagatay, 1998). Biased allocation of resources within households also weakens their capabilities such as health and literacy level. Poor women are more susceptible to biases in labour markets (Kabeer, 1996). In addition, they suffer more from the lack of public services (e.g. problems due to lack of access to toilets). As gender equality is crucial for social and human development of societies, one of the Sustainable Development Goals (SDGs) focuses on gender equality.

The reviewed studies reveal a broad variation in presenting details about gender aspects. While most of the studies have not thoroughly dealt with gender aspects, a few studies have focused on such gender aspects. These studies, for example, have developed guidelines, prescribing designers to give attention to the needs of poor women, have developed design methodologies for craftswomen, or have presented details of how women in a community can contribute towards the implementation of frugal innovations (e.g. Girón et al., 2004; Jagtap and Larsson, 2013). Overall, a broad range exists in dealing with gender aspects in the studies, stressing the need for considering these crucial aspects in design research in this field.

\section{$5 \quad$ Discussion and recommendations}

Many design investigations have been carried out to examine and support the design of frugal innovations in the BOP context. The reviewed literature presents a great diversity in terms of contexts examined. There is also a diversity in how details of contextual aspects are (not) reported. 

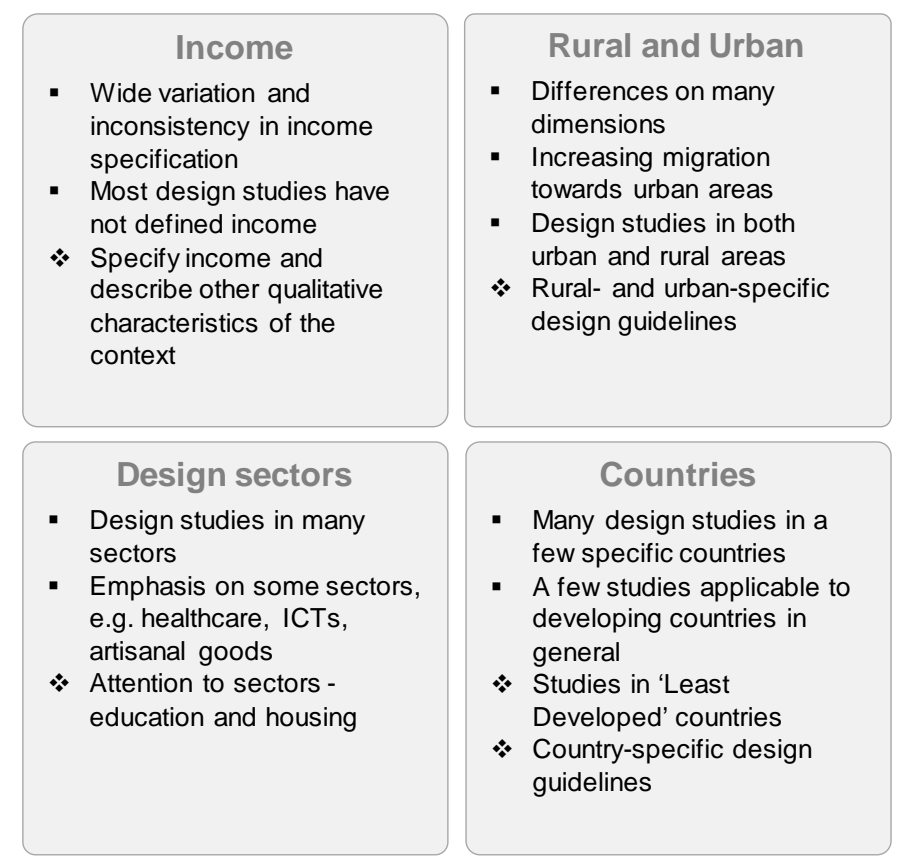

$$
\begin{aligned}
& \text { - findings } \\
& * \text {-recommendations }
\end{aligned}
$$

\section{Gender
- Men and women living in} poverty differ in their needs and views

- Gender equality is crucial in development

- Wide variation in providing details about gender aspects

* Gender sensitive design processes and methods

Figure 1. Contextual aspects of the BOP and design of frugal innovations

The review of contextual aspects of the reviewed papers allows suggesting areas for further research in this field (see Figure 1). Some suggestions focus on reporting details of contextual aspects. Overall, there is a need to report detailed information on the characteristics of the context in which studies are undertaken. Researchers can add such detailed information in scientific articles, for example, by adding supplements as scientific journals typically allow supplements. Detailed information on contextual aspects can help in understanding commonalities and differences between various contexts, providing a basis for making potential generalisations or explaining variations in findings obtained from similar or dissimilar contexts. Konda et al.'s (1992) concept of 'shared memory' in design also supports the need of providing rich and detailed information on contexts examined. In design, shared memory helps in developing better understanding of design situations and related contexts. Providing detailed contextual information about marginalised communities and influence of frugal innovations on those communities is essential to determine if those innovations can be applicable and used in other communities. In order to avoid reuse of failed innovations, it is crucial to have access to rich and detailed information on related contexts of marginalised settings in which those innovations were unsuccessful. Reporting the details of contextual aspects is also crucial to establish external validity of a study that is - to assess the degree to which the conclusions of a study can be applicable to other marginalised settings. Various contextual aspects, as identified and examined in the present paper, can usefully provide an initial basis for reporting a study carried out in marginalised contexts. It is expected that this review of contextual aspects will 
motivate scholars to identify further contextual aspects (if any) of marginalised communities.

In addition to providing thorough information on contextual aspects, future research in this field can benefit from using appropriate research methods to glean information on such contextual aspects. For example, since men and women living in marginalised societies largely differ in their needs and views on problems, it is important to adopt gender sensitive research methods in collecting information on contextual aspects.

Future research in this field can also benefit from examining areas that are not explored. For instance, because many design studies are undertaken in a few specific countries, further research ought to be undertaken in other countries, specifically in countries from the 'least developed' category of the DAC's categorisation of developing countries (DAC, 2016). Furthermore, the diversity across developing counties, rural and urban areas, and sectors can provide promising and fascinating opportunities for future research in this field. As such, future research can aim at developing and evaluating rural- and urban-specific design guidelines or at supporting design in sectors such as housing and education. It is also crucial to develop and evaluate gendersensitive design methods and processes to support design of frugal innovations for both men and women living in BOP societies.

To summarise, whilst design research in the context of marginalised societies can potentially create impact on design practice and education in this field, it can gain from a more rigorous approach. This involves, for example, thoroughly reporting details of contextual aspects and related methodologies. We hope that this work can motivate and support researchers to examine the recommended avenues, as they are crucial for practice, education and research of designing frugal innovations in this field.

\section{References}

1. Alkire, S., Chatterje, M., Conconi, A., Seth, S., \& Vaz, A. (2014). Poverty in Rural and Urban Areas: Direct comparisons using the global MPI 2014.

2. Aranda Jan, C. B., Jagtap, S., \& Moultrie, J. (2016). Towards a framework for holistic contextual design for low-resource settings. International Journal of Design, 10(3), 43-63.

3. Bucciarelli L (1994) Designing engineers. MIT, Cambridge.

4. Cagatay, N. (1998). Gender and poverty. UNDP, Social Development and Poverty Elimination Division.

5. Cai, J., Yang, D., \& Li, D. (2007). Designing the right IT services for the bottom of the pyramid. Communications of the Association for Information Systems, 19(1), 22.

6. DAC, http://www.oecd.org/dac/stats/documentupload/DAC\%20List\%20of\%20ODA\%20Recipie nts\%202014\%20final.pdf, last accessed January 2016.

7. Donaldson, K. (2009). The future of design for development: three questions. Information Technologies \& International Development, 5(4), pp-97.

8. Girón, J. D. L. P., Domínguez Hernández, M. L., \& Jiménez Castañeda, J. C. (2004). Participatory methodologies and the product development process: the experience of Mixtec craftswomen in Mexico. Development in Practice, 14(3), 396-406. 
9. Guimarges, L. E., Penny, J. E., \& Moody, S. (1996). Product design and social needs: the case of North-East Brazil. International Journal of Technology Management, 12(7-8), 849864.

10. Gupta, A. K. (2016). Grassroots innovation: Minds on the margin are not marginal minds. Random House India.

11. Jagtap, S. (2019a). Design and Poverty: A Review of Contexts, Roles of Poor People, and Methods. Research in Engineering Design, 30(1), 41-62.

12. Jagtap, S. (2019b). Key Guidelines for Designing Integrated Solutions to Support Development of Marginalised Societies. Journal of Cleaner Production, 219, 148-165.

13. Jagtap, S. (2019c). Design creativity: Refined method for novelty assessment. International Journal of Design Creativity and Innovation, 7(1-2), 99-115.

14. Jagtap, S. and P. Kandachar (2010). Representing Interventions from the Base of the Pyramid. Journal of Sustainable Development, 3(4), 58-73.

15. Jagtap, S., A. Larsson (2013). Design of Product Service Systems at the Base of the Pyramid. In: Chakrabarti A, Prakash RV, editors. ICoRD'13. Lecture Notes in Mechanical Engineering: Springer India; p. 581-92.

16. Jagtap, S., A. Larsson, et al. (2013). Design and development of products and services at the Base of the Pyramid: a review of issues and solutions. International Journal of Sustainable Society, 5(3), 207-231.

17. Jagtap, S., Larsson, A., Hiort, V., Olander, E., Warell, A. \& Khadilkar, P. (2014). How design process for the Base of the Pyramid differs from that for the Top of the Pyramid. Design Studies, 35(5), 527-558.

18. Kabeer, N. (1996). Agency, well-being \& inequality: Reflections on the gender dimensions of poverty. IDS bulletin, 27(1), 11-21.

19. Kang, L. (2016). Social design as a creative device in developing Countries: The case of a handcraft pottery community in Cambodia. International Journal of Design, 10(3), 65-74.

20. Karnani, A. (2011). Fighting poverty together-Rethinking strategies for business, governments, and civil society to reduce poverty. New York, NY: Palgrave Macmillan.

21. Konda, S., Monarch, I., Sargent, P., \& Subrahmanian, E. (1992). Shared memory in design: a unifying theme for research and practice. Research in Engineering design, 4(1), 2342.

22. Minneman S, Leifer L (1993) Group engineering design practice: the social construction of a technical reality. In: Proceedings of the International Conference on Engineering Design (ICED), The Hague.

23. Murcott, S. (2007). Co-evolutionary design for development: influences shaping engineering design and implementation in Nepal and the global village. Journal of International Development, 19(1), 123-144.

24. Narayan, D., Chambers, R., Shah, M.K. and Petesch, P. (2000) Voices of the Poor: Crying Out for Change. New York: The World Bank - Poverty Division (PRMPO).

25. Nielsen, C., \& Samia, P. M. (2008). Understanding key factors in social enterprise development of the BOP: A systems approach applied to case studies in the Philippines. Journal of Consumer Marketing, 25, 446-454.

26. Olinto, P., Beegle, K., Sobrado, C., \& Uematsu, H. (2013). The state of the poor: Where are the poor, where is extreme poverty harder to end, and what is the current profile of the world's poor?. Economic Premise, 125(2).

27. Papanek, Victor, and R. Buckminster Fuller. Design for the real world. London: Thames and Hudson, 1972.

28. Prahalad, C. K. (2004). The fortune at the Bottom of the Pyramid: Eradicating poverty through profits. Upper Saddle River: NJ: Wharton School Publishing. 
29. Prahalad, C. K., \& Hart, S. (1999). Strategies for the bottom of the pyramid: Creating sustainable development (Working paper). Ann Arbor: University of Michigan. Retrieved from http://www.bus.tu.ac.th/usr/wai/xm622/conclude\%620monsanto/ strategies.pdf

30. Radjou, N., Prabhu, J., \& Ahuja, S. (2012). Jugaad innovation: Think frugal, be flexible, generate breakthrough growth. New York, NY: Wiley.

31. Schumacher EF. Small is beautiful: economics as if people mattered. New York: Harper and Row; 1973.

32. Subrahmanian, E., Eckert, C., McMahon, C., \& Reich, Y. (2017). Economic development as design: Insight and guidance through the PSI framework. International Conference on Engineering Design, ICED17, Vancouver, Canada.

33. Thomas, A. (2006). Design, poverty, and sustainable development. Design Issues, 22(4), 54-65.

34. UN (2017), http://unohrlls.org/about-ldcs/, last accessed July 2017.

35. Viswanathan, M., and J. A. Rosa. 2007. Product and market development for subsistence marketplaces: Consumption and entrepreneurship beyond literacy and resource barriers. In Advances in international management series, ed. J. Cheng and M. Hitt, 1-17. Oxford, UK: Elsevier.

36. Whitney, P., \& Kelkar, A. (2004). Designing for the Base of the Pyramid. Design Management Review, 15(4), 41-47.

37. Wicklein, R. C. (1998). Designing for appropriate technology in developing countries. Technology in Society, 20(3), 371-375.

38. World Bank, 2010, “World Development Indicators,” World Bank Publications, Washington, DC. 